\title{
HIV-1 gp120-Induced Tubular Epithelial Cell Apoptosis Is Mediated Through p38-MAPK Phosphorylation
}

\author{
Aditi A. Kapasi, ${ }^{2}$ Geeta Patel, ${ }^{2}$ Nicholas Franki, ${ }^{2}$ and Pravin C. Singhal ${ }^{1,2}$ \\ ${ }^{1}$ Immunology and Inflammation Center for Excellence, North Shore-Long Island Jewish Research Institute, \\ Manhasset, New York, USA \\ ${ }^{2}$ Division of Kidney Diseases and Hypertension, Long Island Jewish Medical Center, New Hyde Park, \\ New York, USA
}

Accepted September 23, 2002

\begin{abstract}
Background: HIV-associated nephropathy is accompanied by significant tubular alterations in the form of tubular cell proliferation, apoptosis, and microcystic dilatation. In the present study we evaluated the role of CD4 receptors in HIV-1-induced tubular cell injury.

Methods: To confirm the presence of CD4 receptors in tubular cells, immunocytochemical, Western and Northern blot studies were carried out. To determine the downstream effect of CD4 and gp120 interaction, we evaluated the effect of gp120 on tubular cell p38 mitogen-activated protein kinase (MAPK) activity and phosphorylation. To establish causal relationships between gp120, CD4, and p38 MAPK pathways, we studied the effect of anti-CD4 antibody and SB 202190 (an inhibitor of p38 MAPK) on gp120-induced tubular cell apoptosis.
\end{abstract}

Results: Proximal tubular cells in culture as well as in intact tissue showed expression of CD4 (immunocytochemical and Western blot studies). Cultured tubular cells also showed mRNA expression for CD4 (Northern blot studies). Gp120, at concentrations of 10-100 ng/ $\mathrm{ml}$, triggered tubular cell apoptosis; however, this effect of gp 120 was inhibited by anti-CD4 antibody. SB 202190 also inhibited gp120-induced tubular cell apoptosis. In addition, gp 120 promoted tubular cell p38 MAPK phosphorylation in a time- and dosedependent manner.

Conclusion: Gp120 through interaction with CD4 triggers tubular cell apoptosis. This effect of gp120 on tubular cells is mediated through phosphorylation of p38 MAPK.

\section{Introduction}

In the northeastern United States, renal disease has been reported to occur in $10-15 \%$ of patients with AIDS (1). The majority of HIV-1 infected patients with renal disease have features typical of HIV-associated nephropathy (HIVAN). Focal glomerulosclerosis and tubulointerstitial lesions are the predominant features of HIVAN (1-4). Previously, Kimmel et al. (5) demonstrated the presence of HIV-1 genes in renal biopsy tissue. Similarly Cohen et al. (6) showed the presence of HIV genomic material in glomerular and tubular epithelial cells from renal biopsy tissue of HIV-1 infected patients with glomerulosclerosis. Bruggeman et al. (7) demonstrated the presence of HIV-1 in human glomerular epithelial cells. Ray et al. (8) also demonstrated infection of human

Address correspondence and reprint requests to: Pravin C. Singhal, MD, Division of Kidney Diseases, Long Island Jewish Medical Center, New Hyde Park, NY 11040. Phone: 718-470-7360; fax: 718-470-6849; e-mail: singhal@lij.edu. primary renal tubular epithelial cells with HIV-1. However, these investigators suggested that entry of HIV-1 into these tubular cells was through a nonCD4 pathway (8). Recently, Conaldi et al. (9) in in vitro studies demonstrated that human renal tubular cells express CD4 receptors and HIV-1 kills tubular epithelial cells by triggering an apoptotic pathway. We also reported the presence of CD4 receptors in human tubular cells in culture as well as in renal tissue (10).

HIV-1 gpl60 protein (specific ligand for CD4 receptors) has been reported to have a bimodal effect on tubular cell growth; it induces proliferation at lower concentrations and apoptosis at higher concentrations $(11,12)$. Apoptosis is programmed cell death occurring in both physiologic and pathologic conditions in response to various stimuli originating from either within or outside the cell (13). Apoptosis is usually in balance with cellular differentiation and multiplication. The initial stimulus induces activation of intracellular transduction pathways including 
mitogen-activated protein (MAP) kinases (MAPKs) (14). MAPKs are a crucial part of the cellular signal transduction machinery and play major roles in cell growth, differentiation, and transformation (15).

In humans, CD4 not only serves as the receptor for HIV but also contributes to specific cell-cell adhesion (16-19). Interaction between CD4 and HIV-1 envelope glycoprotein, gp 120 (major fraction of gp 160 protein), may proceed with activation of intracellular signaling including phosphorylation of protein tyrosine kinase, Pyk2 (20). Pyk2 is phosphorylated on tyrosine either after $G$ protein coupled receptors bind to a ligand or after interaction with agents that elevate intracellular $\mathrm{Ca}^{2+}$ concentration (20). Recently, in neurons, HIV-1 and its coat protein gp 120 have been demonstrated to promote apoptosis and activation of $c$-Jun NH2-terminal protein kinases (JNK) and mitogen activated protein kinases (21). The MAPK family includes the JNKs, extracellular signal-regulated kinases (ERKs), and p38 MAPKs. Various stress stimuli, including ultraviolet irradiation, cytokines, and free radicals, induce apoptosis through the activation of either JNK or P38 MAPK $(14,15)$. On the other hand, mitogenic stimuli activate the ERK pathway $(14,15)$. Both JNK and p38 MAPKs have been shown to phosphorylate and activate transcription factors (involved in proliferative and apoptotic pathways) directly, thus regulating gene expression in response to stimuli that activate them (22). All three kinases (ERK, JNK, and P38 MAPK) have been shown to be activated in cultured renal cells by a number of different stimuli (23).

We hypothesize that gp 120 protein through interaction with the CD4 receptor activates tubular cell p38 MAPK pathways to initiate the synthesis of transcription factors. To test this hypothesis we studied the effect of gp120 on MAPK activity and phosphorylation. To confirm the role of gp120-induced tubular cell MAPK activation, we examined the effect of SB 202190, a selective inhibitor of p38 MAPK, on gp120-induced tubular cell apoptosis. To establish a relationship between gp 120 and CD4 receptors, we evaluated the effect of anti-CD4 antibody on gp 120-induced tubular cell apoptosis.

\section{Materials and Methods Cell Culture}

Human proximal tubular cells (proximal tubular cells from a normal adult male immortalized by transduction with human papilloma virus E6/E7 genes, Cat \# CRL 2190) were obtained from the American Type Culture Collection (ATCC, Manassas, VA, USA). These cells were plated in $75-\mathrm{cm}^{2}$ flasks and incubated in keratinocyte media containing penicillin $(50 \mathrm{U} / \mathrm{ml}$, GIBCO, Grand Island, NY, USA), and streptomycin (GIBCO, $50 \mu \mathrm{g} / \mathrm{ml}$ ) in an environment of $5 \% \mathrm{CO}_{2}$ and $95 \%$ air at $37^{\circ} \mathrm{C}$. Cells were grown to subconfluence for all the experimental conditions.
Human T cells (Jurkat cells), mouse macrophage cell line (J774), and rat kidney (NRK) cells were obtained from ATCC. Human glomerular epithelial cells (HGEC) were used as a positive control; their characterization has been reported previously (24-26).

Rabbit anti-human antibody to CD4 was obtained from NIH Research and Reagent Program (Rockville, MD, USA) and goat polyclonal antibody to CD4 from Santa Cruz Biotechnology Inc. (Santa Cruz, CA, USA). Secondary goat anti-rabbit HRPlabeled antibody was obtained from Santa Cruz. Biotinylated goat anti-rabbit antibody was obtained from Vector Laboratories (Burlingame, CA, USA). HIV-1 gp120 (soluble native gp120 of HIV-1 ${ }^{451}$, affinity purified from the culture medium of HIV-1 infected human $\mathrm{T}$ cells) was obtained from Advanced Biosciences Laboratories (Kensington, MD, USA). HIV-1 mutant gpl20 (with aminoacid sequence [REQFGNNKTIIFKQSSGGDPEIVTHSFNC] blockade of CD4 and gp120 interaction) was obtained from NIH Research and Reagent Program. The total p38MAPK goat polyclonal antibodies were purchased from Santa Cruz. Phospho-p38 MAPK (rabbit polyclonal) was obtained from New England Biolabs Inc. (Beverly, MA, USA). Substrate for p38 MAPK, activating transcription factor 2 (ATF-2, 1-96), was obtained from Santa Cruz. SB202190, a selective inhibitor for p38 MAPK was purchased from Calbiochem (La Jolla, CA, USA). Hoechst dye $(\mathrm{H}-33342)$ was obtained from Molecular Probes (Eugene, OR, USA), and propidium iodide was purchased from Sigma Chemical Co. (St. Louis, MO, USA). Monoclonal anti-PCNA antibodies were obtained from Santa Cruz Biotechnology Inc.

\section{Human Renal Tissue}

Human renal tissue was obtained from microscopically normal areas of nephrectomy specimens from renal cancer patients.

\section{Morphologic Studies}

To determine the occurrence of apoptosis, equal numbers of cells were incubated under control and experimental conditions. At the end of the incubation periods, cells were treated with H-33342 ( $1 \mu \mathrm{g} / \mathrm{ml}$ ) for $7 \mathrm{~min}$ at $37{ }^{\circ} \mathrm{C}$. Subsequently, cells (without a wash) were placed on ice and propidium iodide (final concentration, $1 \mu \mathrm{g} / \mathrm{ml}$ ) was added to each well. Cells were incubated with the dyes for $10 \mathrm{~min}$ on ice, protected from light, and examined under ultraviolet light. The percentages of live and apoptotic cells were recorded in eight random fields by two observers unaware of experimental conditions. Hoechst stains the nuclei of live cells and identifies apoptotic cells by increased fluorescence whereas propidium iodide costains the necrosed cells. Double staining by these two agents enables us to obtain the percentage of live, necrosed, and apoptotic cells (27). To confirm the occurrence of apoptosis, we also stained the cells by TUNEL 
method (kit supplied by Roche Applied Science, Indianapolis, IN, USA).

To determine the occurrence of proliferation, equal numbers of growth-arrested cells (serum starved for $48 \mathrm{hr}$ in $0.1 \%$ BSA and $5 \%$ ITS containing growth-arrest medium) were incubated under control and experimental conditions followed by labeling for proliferating cell nuclear antigen (PCNA) as described below. PCNA-positive cells were counted in eight random fields and percent of PCNA positive cells were calculated per field. Each experiment was performed in triplicate.

\section{Immunocytochemical Labeling for PCNA}

In brief, HK-2 cells were grown on chamber slides, fixed, incubated with $1.5 \%$ normal goat serum for $20 \mathrm{~min}$, followed by incubation with primary antibody, PCNA (1:5000; Santa Cruz) for $60 \mathrm{~min}$. After removing unbound primary antibody and rinsing with phosphate-buffered saline (PBS), cells were incubated with biotinylated goat anti-rabbit antibody (1:200; Vector Laboratories) for $60 \mathrm{~min}$. Cells were rinsed and then incubated with avidinbiotinylated HRP (Vectastain Elite ABC Kit; Vector Laboratories) for $30 \mathrm{~min}$, followed by incubation with $0.1 \%$ diaminobenzidine tetrahydrochloride (Sigma) in $d / w$ containing urea and then mounted. Experimental negative controls consisted of substituting the primary antibody with PBS.

\section{Immunohistochemical Studies for CD4 Expression (Human Renal Tissue Sections)}

Renal cortical tissues were fixed in formalin, embedded in paraffin, and cut into $5-\mu \mathrm{m}$ thick sections. Serial sections were immunostained using the avidinbiotin peroxidase complex $(\mathrm{ABC})$ method. After deparaffinization, hydration and a quenching step with 3\% hydrogen peroxide in methanol, sections were washed with PBS and blocked with a $1.5 \%$ normal goat serum. The incubation period was 20 min at $22{ }^{\circ} \mathrm{C}$, followed by incubation with rabbit polyclonal anti-human CD4 antibody (1:8000) for 60 min at $22{ }^{\circ} \mathrm{C}$. The rest of the protocol was the same as described above. Negative controls consisted of substituting the primary antibody with nonspecific rabbit IgG. Parallel studies were performed with goat anti-CD4 antibody to confirm the staining pattern.

\section{Western Blotting Studies for CD4 Expression}

Renal tubular cells were grown to subconfluence in 100-mm Petri dishes (human glomerular epithelial cells, U937 cells, Jurkat cells, and mouse macrophage cell line [J774] were used as positive controls and normal rat kidney cells as a negative control). Petri dishes with subconfluent cells were placed on ice and washed with ice-cold PBS. Subsequently, cells were scraped in a modified ice-cold RIPA lysis buffer. To shear the DNA, the scraped cell solution was transferred, in a syringe fitted with a 21-gauge needle, to a microcentrifuge tube and cell lysates were passed through the needle several times. Tubes were incubated for another $30-60 \mathrm{~min}$ on ice. The cell lysates were centrifuged at $15,000 \times \mathrm{g}$ for $20 \mathrm{~min}$ at $4{ }^{\circ} \mathrm{C}$. The supernatant (total cell lysate) was analyzed for total protein content. The proteins $(20 \mu \mathrm{g} /$ lane) extracted from the tubular cell lysates were separated on a $10 \%$ polyacrylamide (PAGE) precast gel (Bio-Rad, Hercules, CA, USA) and transferred onto a nitrocellulose membrane using a Bio-Rad miniblot apparatus. Nitrocellulose membranes were then processed further for immunostaining with anti-CD4 antibody and followed with HRP-labeled secondary antibody. The blots were developed using a chemiluminescence detection kit (Santa Cruz) and were exposed to $\mathrm{x}$-ray film. Parallel studies were performed with goat anti-CD4 antibody to confirm the expression of CD4.

Renal cortical tissue was homogenized in RIPA buffer with protease inhibitors and was separated on $10 \%$ PAGE, immunoprecipitated with specific anti-CD4 antibody, immunoblotted with HRP-labeled anti-rabbit antibody, and detected using an ECL kit. Three sets of experiments were carried out.

\section{Northern Blotting Studies for mRNA Expression of CD4}

To determine tubular cell mRNA expression of CD4, cells were grown to subconfluence $\left(5 \times 10^{5}\right.$ cells/ dish) in Petri dishes. In addition, human glomerular epithelial cells, human $\mathrm{T}$ cells (Jurkat cells), and human monocytes (U937) were used as positive controls; human lung fibroblasts were used as a negative controls. Cells were washed twice with PBS. Total RNA was extracted from lysates of confluent cells by the method of Chomczynski and Sacchi (28). Aliquots of total RNA $(20 \mu \mathrm{g})$ were treated with formamide and formaldehyde, electrophoresed in a $1.2 \%$ agarose-formaldehyde gel, and transferred to Hybond-N nylon membranes. The gel was stained with ethidium bromide to determine the size as well as amount of RNA. CDNA probes specific for CD4 (NIH Reagent Program) were labeled with $\alpha-\left[{ }^{32} \mathrm{P}\right]-$ dCTP using a random primed DNA labeling kit. Filters were hybridized at $42{ }^{\circ} \mathrm{C}$ for $16 \mathrm{hr}$ with the labeled cDNA probe. The membranes were washed to a final high stringency with $0.2 \times$ SSC, $0.1 \%$ SDS for $1 \times 30 \mathrm{~min}$ at $65{ }^{\circ} \mathrm{C}$. After washing, the membranes were kept in contact with XAR-5 film and an intensifying screen at $-70{ }^{\circ} \mathrm{C}$ and developed.

\section{Studies Pertaining to 38 MAPK Activity and Phosphorylation}

Equal numbers of cells were incubated under control and experimental conditions. At the end of the incubation period, cells were pelleted, resuspended in ice-cold lysis buffer $(20 \mathrm{mM}$ of Tris, $\mathrm{pH} 7.5,137$ $\mathrm{mM}$ of NaCl, $2 \mathrm{mM}$ of EDTA, pH 7.4, $1 \%$ Triton X$100,25 \mathrm{mM}$ of $\beta$-glycerophosphate, $1 \mathrm{mM}$ of sodium orthovanadate, $2 \mathrm{mM}$ of sodium pyrophosphate, $1 \mathrm{mM}$ of phenylmethanesulfonyl fluoride, and $10 \mu \mathrm{g} / \mathrm{ml}$ of aprotinin), vortexed to disrupt the cells, 
and assayed for protein content with a BCA protein measurement kit (Pierce, Rockford, IL, USA). One hundred to one hundred fifty micrograms of total crude extract was immunoprecipitated with $5 \mu \mathrm{g}$ of anti-p38 MAPK-antibody-sepharose conjugate. After $\mathrm{l}$ hr at $4{ }^{\circ} \mathrm{C}$, the beads were washed three times with lysis buffer and twice with kinase buffer (25 mM of HEPES, pH 7.4, $25 \mathrm{mM}$ of $\mathrm{MgCl}_{2}, 25 \mathrm{mM}$ of $\beta$-glycerophosphate, $1 \mathrm{mM}$ of $\mathrm{NaVO}_{3}$, and $2 \mathrm{mM}$ of dithiothreitol). Immune complex kinase assays were performed at $37{ }^{\circ} \mathrm{C}$ for $15 \mathrm{~min}$ in a total volume of $30 \mu \mathrm{l}$ of kinase buffer containing the immunoprecipitate, $1 \mu \mathrm{g}$ of substrate (ATF-2), $16 \mu \mathrm{M}$ of unlabeled ATP, and $0.67 \mu \mathrm{Ci}$ of $\left[\gamma^{32} \mathrm{P}\right]$ ATP $(6000 \mathrm{Ci} / \mathrm{mmol} ; 10 \mathrm{mCi} / \mathrm{ml})$. The reaction was terminated with Laemmli buffer containing dithiothreitol. Samples were boiled and resolved on a $15 \%$ sodium dodecyl sulfate-polyacrylamide gel and transferred to a PVDF membrane (Bio-Rad) in $192 \mathrm{mM}$ of glycine, $25 \mathrm{mM}$ of Tris-base, and $20 \% \mathrm{v} / \mathrm{v}$ methanol overnight at $20 \mathrm{~V}$. After transfer, the blot was wrapped in plastic wrap and exposed to $\mathrm{x}$-ray film with an intensifying screen at $-70^{\circ} \mathrm{C}$ overnight. Three series of experiments were carried out.

To confirm the role of MAPK activity, we studied the effect of SB 202190, a selective inhibitor of p38 MAPK, on gp120-induced tubular cell P38 MAPK activation. In brief, equal numbers of growtharrested tubular cells were treated under control and experimental conditions. Subsequently, cells were processed for immune complex kinase assay (29).

\section{Immunoprecipitation Studies Using Phospho-antibodies}

The activation of MAPKs requires specific phosphorylation of the threonine and tyrosine residues within the TXY motif (30). Equal numbers of cells were incubated under control and experimental conditions. At the end of the incubation period, cells were lysed in ice-cold RIPA buffer as mentioned earlier. Three hundred micrograms of proteins were subjected to immunoprecipitation with $5 \mu \mathrm{l}$ of phospho-p38MAPK (rabbit polyclonals, New England Biolabs) in $200 \mu \mathrm{l}$ of an IP buffer containing $50 \mathrm{mM}$ of EDTA and $3 \%$ Nonidet P-40, and were placed on a shaker for $1 \mathrm{hr}$ at $4{ }^{\circ} \mathrm{C}$. Then, $30 \mu \mathrm{l}$ of protein A/G plus sepharose beads were added and the rotation was continued for the next $2 \mathrm{hr}$. Subsequently, beads were washed twice with IP buffer and twice with a solution of $12.5 \mathrm{mM}$ of ß-glycerol phosphate, $20 \mathrm{mM}$ of MOPS ( $\mathrm{pH} 7.2$ ), $5 \mathrm{mM}$ of EGTA, $7.5 \mathrm{mM}$ of $\mathrm{MgCl}_{2}, 50 \mathrm{mM}$ of NAF, and $0.25 \mathrm{mM}$ of DTT. The beads were resuspended in sample buffer, subjected to Western blotting with goat anti-p38 MAPK antibody, immunoblotted with HRP-labeled anti-goat antibody, and detected by ECL (Pierce).

\section{ELISA for Caspase-3 Activity}

Equal numbers HK-2 cells were incubated in media containing either buffer (control) or gpl20 (1, 10, and $100 \mathrm{ng} / \mathrm{ml}$ ) for $16 \mathrm{hr}$. At the end of the incuba- tion period, cells were harvested and prepared for the measurement of caspase- 3 activity with the use of Caspase-3 assay kit (Casp-3-C, Sigma).

\section{Statistical Analysis}

For comparison of mean values between two groups, the unpaired $t$-test was used. To compare values among multiple groups, ANOVA was applied and a Newman-Keuls multiple-range test was used to calculate a $q$ value. All values are means \pm SEM except where otherwise indicated. Statistical significance was defined as $p<0.05$.

\section{Results}

Morphologic Studies

To determine the dose response effect of gp120, equal numbers of tubular cells were incubated either with buffer (control) or variable concentrations of gp120 protein (1-100 ng/ml) for $24 \mathrm{hr}$. Subsequently cells were assayed for apoptosis (H-33342 and propidium iodide; TUNEL method). Representative micrographs of tubular cells treated under control and experimental conditions are shown in Figure 1A (a, b, c, and d). gp120 promoted tubular cell apoptosis in a dose-dependent manner (Fig. 2A).

To determine the role of gp 120 motif binding to CD4, we studied the effect of HIV-1 mutant gp120. Equal numbers of tubular cells were incubated in media containing either buffer (control) or HIV-1 mutant gp $120(0.01-100.00 \mathrm{ng} / \mathrm{ml})$ for $18 \mathrm{hr}$. Subsequently, cells were stained for apoptosis. As shown in Figure 2B, mutant gp 120 did not modulate tubular cell apoptosis. These findings suggest that an alteration of the gp120-binding motif attenuates CD4-induced downstream signaling.

To establish a relationship between gp 120 protein and CD4 receptor interaction, equal numbers of tubular cells were incubated either with buffer (control), anti-CD4 antibody ( $1 \mu \mathrm{g} / \mathrm{ml})$, or gp 120 protein $(10-100 \mathrm{ng} / \mathrm{ml})$ with or without anti-CD4 antibody (cells were primed with anti-CD4 antibody $2 \mathrm{hr}$ prior to the addition of gp 120) for $18 \mathrm{hr}$. gp 120 promoted tubular cell apoptosis (Fig. 2C); however, anti-CD4 antibody inhibited $(p<0.001)$ the gp120induced tubular cell apoptosis.

To determine the role of MAPK activity in gp120-induced apoptosis, we studied the effect of SB 202190, a selective inhibitor of p38 MAPK. Equal numbers of tubular cells were treated either with buffer (control), SB $202190(5 \mu \mathrm{M})$, gp 120 protein $(10-100 \mathrm{ng} / \mathrm{ml})$ with or without SB 202190 for $18 \mathrm{hr}$. Subsequently, cells were assayed for apoptosis. gp120 promoted tubular cell apoptosis (Fig. 2D); whereas, SB 202190 attenuated $(p<0.001)$ the gp120-induced tubular cell apoptosis.

To compare the dose-response effect of gp 120 on tubular cell proliferation and apoptosis, we carried out apoptosis and proliferation studies in parallel. Equal numbers of growth-arrested cells were treated 

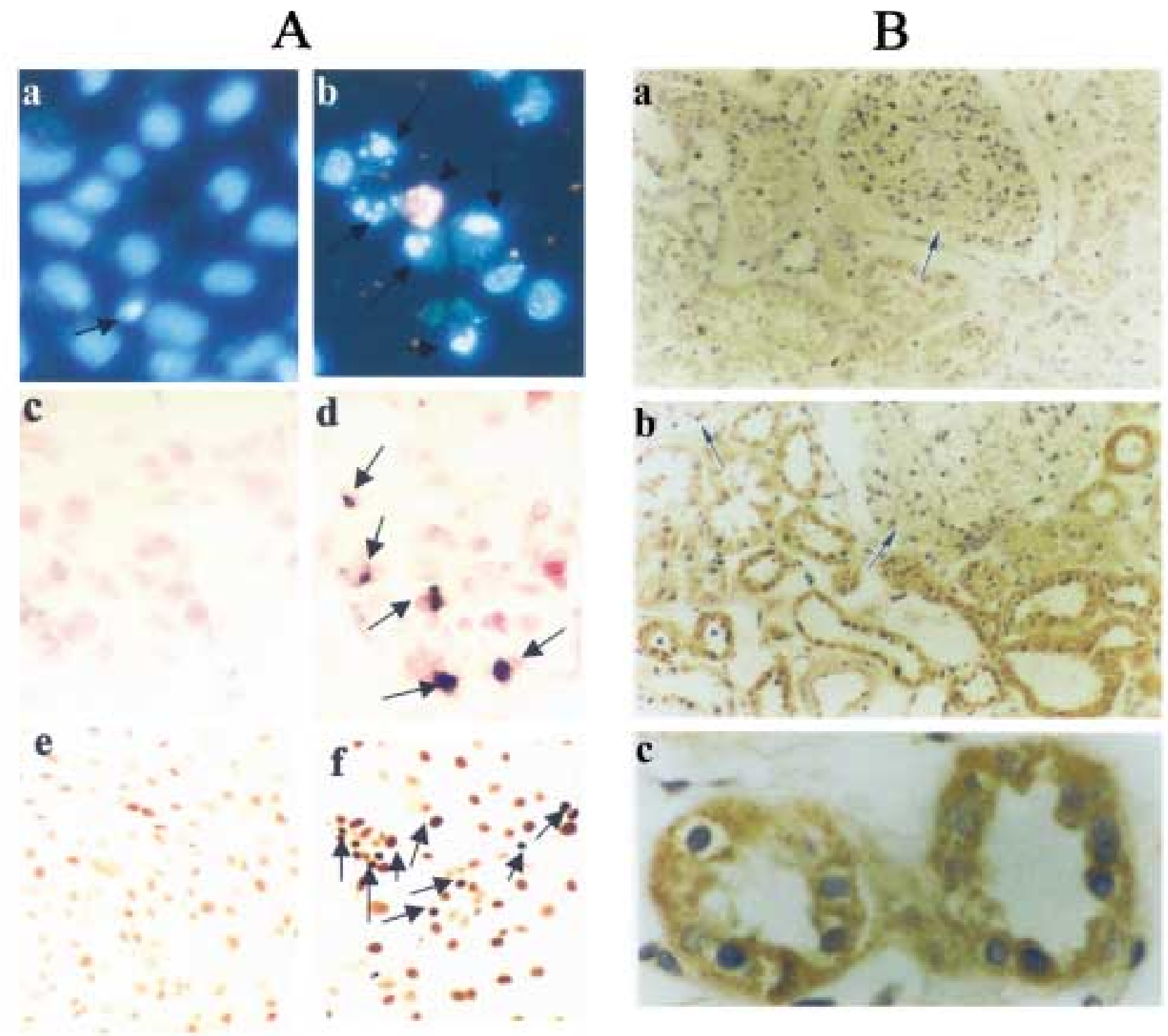

Fig. 1. (A) Effect of gp120 on tubular cell apoptosis and proliferation (Representative micrographs). Equal numbers of HK-2 cells were incubated in media containing either buffer (control) or gp120 (100 ng/ml) for $16 \mathrm{hr}$. At the end of the incubation period, cells were stained with H-33342 and propidium iodide. Representative micrographs are shown (original magnification $400 \times$ ). (a) Control HK-2 cells show stained nuclei. Arrow indicates an apoptotic cell with bright fluorescence and condensed nuclei. (b) HK-2 cells treated with gp120 show many apoptotic cells with bright fluorescence with condensed or fragmented nuclei (arrows). Arrowhead indicates a necrosed cell (stained pink). Equal numbers of HK-2 cells were incubated in media containing either buffer (control) or gp120 (10 ng/ml) for $16 \mathrm{hr}$. Subsequently, cells were assayed for apoptosis by TUNEL method (original magnification $200 \times)$. (c) Control HK-2 cells. (d) HK-2 cells treated with gp 120. Arrows indicate apoptotic cells with darkly stained nuclei. Equal numbers of growth arrested HK-2 cells were incubated in media containing either buffer (control) or gp120 (0.01 ng/ml). Subsequently, cells were labeled for PCNA (original magnification $100 \times$ ). (e) Control HK-2 cells. (f) HK-2 cells treated with gp120. PCNA-labeled nuclei show dark staining (arrows). (B) Immunostaining for tubular cell CD4 receptors in renal cortical tissue section. Formalin-fixed and paraffin-embedded human renal cortical sections were immunostained for CD4 receptors using the ABC method.

(a) Negative control. An arrow indicates a glomerulus. (b) Renal tubular cells showing brown staining for CD4 receptors; glomeruli indicated by arrows (original magnification $200 \times$ ). (c) Tubules indicated by asterix in (b), were further visualized under oil immersion (original magnification $1000 \times$ ).

with variable concentrations of gp $120(0-100 \mathrm{ng} / \mathrm{ml})$. Subsequently, cells were either labeled for PCNA or stained with H-33342. As shown in Figure 2E, gp 120 at lower concentrations increased the number of PCNA positive cells; gp120 at higher concentrations promoted the percentage of apoptotic cells. Representative micrographs of tubular cell PCNA labeling under control and experimental conditions are shown in Figure 1A (e and f). These findings suggest that gp120 has a bimodal effect on tubular cell growth. 


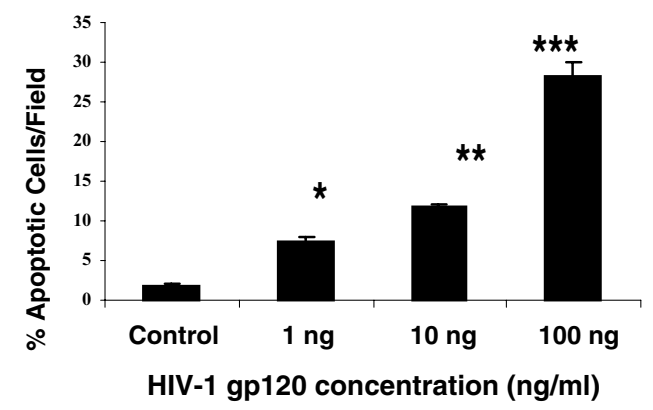

B
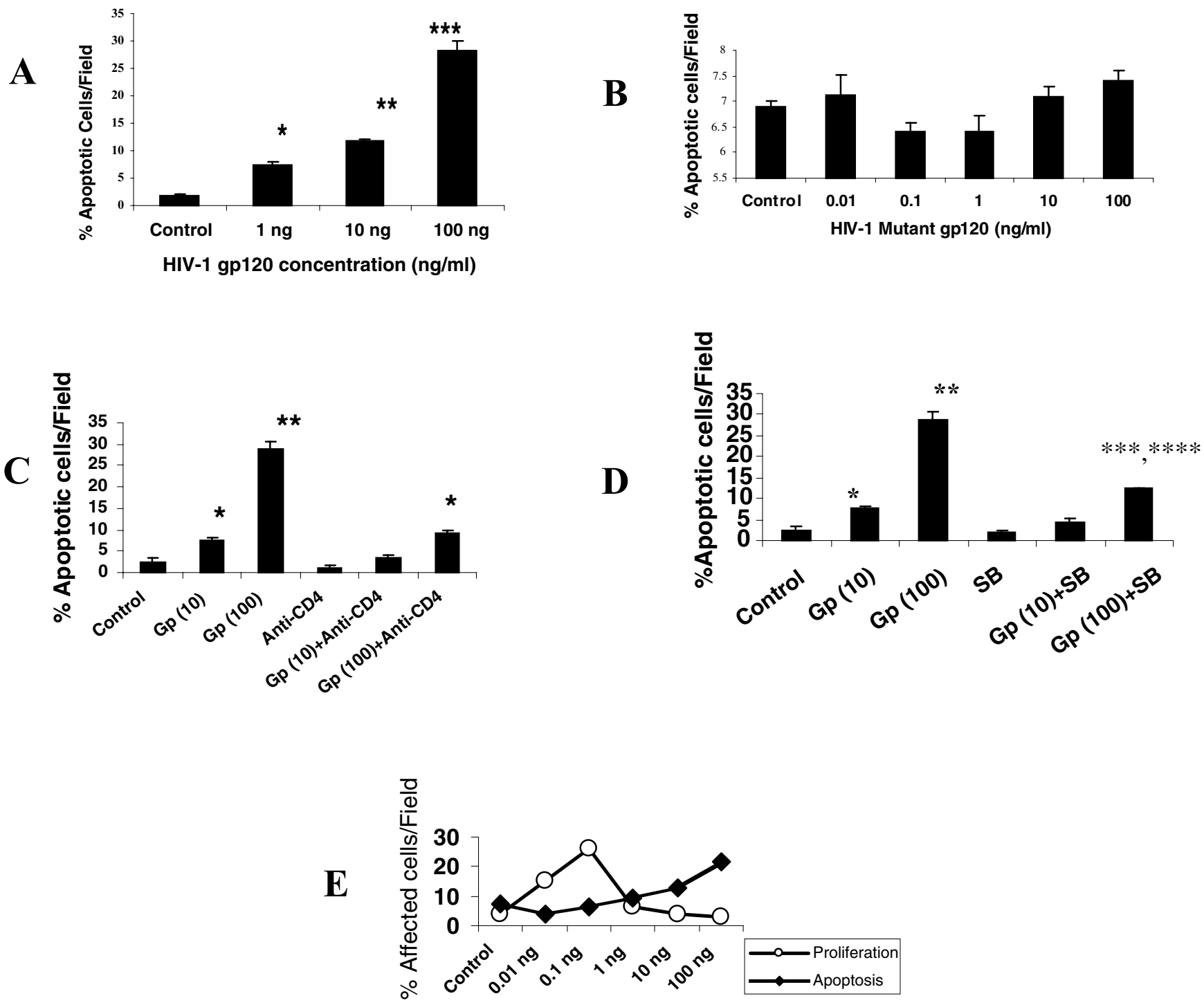

Fig. 2. (A) Dose-response effect of gp120 on tubular cell apoptosis. Equal numbers of HK-2 cells were incubated in media containing either buffer (control) or gp120 (1-100 ng/ml) for $16 \mathrm{hr}$. Subsequently, cells were stained for apoptosis. Results (mean \pm SEM) are from four sets of experiments. ${ }^{*} p<0.01$ compared with control. ${ }^{* *} p<0.01$ compared with control and gp 120 (1 ng); ${ }^{* *} p<0.001$ compared with control and gp120 (1-10 ng). (B) Effect of HIV-1 mutant gp120 on tubular cell apoptosis. Equal numbers of tubular cells were incubated in media containing either buffer (control) or HIV-l mutant gp 120 (0.01-100.00 ng/ml) for $16 \mathrm{hr}$. Subsequently, cells were stained for apoptosis. Results (mean \pm SEM) are from four sets of experiments. (C) Effect of anti-CD4 antibody on gp120induced tubular cell apoptosis. Equal numbers of HK-2 cells were incubated in media containing either buffer (control), gp120 (10 $\mathrm{ng} / \mathrm{ml}$, gp 10), gp120 (100 ng/ml, gp 100), anti-CD4 antibody $(1 \mu \mathrm{g} / \mathrm{ml})$, or gp120 + anti-CD4 antibody (cells were primed with antiCD4 antibody $2 \mathrm{hr}$ prior to addition of gp 120) for $18 \mathrm{hr}$. Subsequently, cells were stained for apoptosis. Results (mean \pm SEM) are from four sets of experiments. ${ }^{*} p<0.001$ compared with control and anti-CD4. ${ }^{* *} p<0.001$ compared with control, gp120 (10 ng), gp120 (10 ng) + anti-CD4, and gp120 (100 ng) + anti-CD4. (D) Effect of p38 MAPK inhibitor (SB 202 190) on gp 120-induced tubular cell apoptosis. Equal numbers of HK-2 cells were incubated in media containing either buffer (control), gp 120 (10 ng/ml, gpl0), gp120 (100 ng/ml, gp 100), SB 202190 (SB, $5 \mu \mathrm{M})$, or gp120 + SB 202190 (cells were primed with SB 202 190, 2 hr prior to addition of gp 120) for $18 \mathrm{hr}$. Subsequently, cells were stained for apoptosis. Results (mean \pm SEM) are from four sets of experiments. ${ }^{*} p<$ 0.01 compared with control. ${ }^{* *} p<0.001$ compared with control, gp120 (10 ng), gp120 (10 ng) + SB202190, and gpl20 (100 ng) + SB202190. ${ }^{* * *} p<0.01$ compared with gp120 (10 ng) + SB202190. ${ }^{* * * *} p<0.001$ compared with control, SB 202190, and gp120 (10 $\mathrm{ng})+$ SB202190. (E) Effect of gp120 on proliferative and apoptosis indices. Equal numbers of growth-arrested cells were treated either with media alone (control) or variable concentrations of gp120 (0.01-100.00 ng/ml). Subsequently, cells were labeled either for PCNA or with H-33342.

\section{Studies Pertaining to CD4 Expression}

In renal tissue sections, tubular cells showed staining for CD4 (Fig. 1B). Western blots prepared from renal tissue and probed for CD4 showed expression of CD4 (Fig. 3A). Cultured proximal tubular cells also showed expression of CD4 (Fig. 3B). Positive controls, including human glomerular epithelial cells, U937 cells, mouse macrophage cell line (J774) 
A
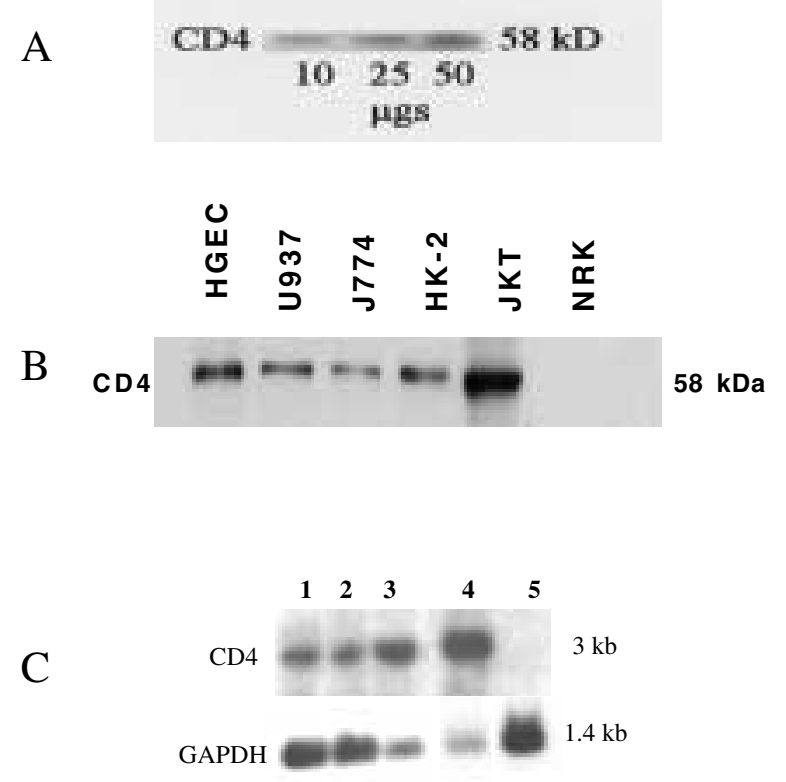

Fig. 3. (A) Western blotting for renal cortical tissue CD4 detection. Human renal cortical tissue was homogenized in RIPA buffer with protease inhibitors. Subsequently, 10, 25, or $50 \mu \mathrm{g}$ of protein/lane was loaded, separated on PAGE, immunoprecipitated with specific antibody for CD4, immunoblotted with HRP-labeled anti-rabbit IgG, and detected by ECL. All samples showed a band of 58-kDa protein. (B) Western blotting for tubular cell CD4 detection. HGEC, human T cells (Jurkat cells, JKT), mouse macrophage cell line (J774), and human monocyte cell line (U937) were used as positive controls; normal rat kidney (NRK) cells were used as a negative control. Human proximal renal tubular cells (HK2) and other cells were grown to subconfluence, cells were lysed, protein extracted, Western blots generated and probed for CD4. HK2, HGEC, JKT, J774, and U937 cells show a 58-kDa band, whereas NRK did not show 58-kDa band. (C) Tubular cell mRNA expression of CD4. A representative Northern blot showing mRNA expression of CD4 receptors by human proximal tubular epithelial cells (lane 2). Similarly, glomerular epithelial cells (lane 1), U937 (lane 3), and Jurkat cells (lane 4) showed mRNA expression of CD4. However, human lung fibroblasts (negative control, lane 5) did not show CD4 mRNA expression.

and Jurkat cells, also showed expression of CD4; rat kidney cells did not show CD4 expression. Cultured proximal tubular cells showed mRNA expression of CD4 (Fig. 3C). Positive controls, including U937, Jurkat cells, and glomerular epithelial cells, also showed mRNA expression of CD4; human lung fibroblasts (negative controls) did not show mRNA expression of CD4.

\section{Studies Pertaining to Activity of MAPK Cascade}

To evaluate the dose-response effect of HIV-1 gp120 on tubular cell MAPK activation and phosphorylation, equal numbers of growth-arrested tubular cells were treated with either buffer (control) or variable concentrations of gp 120 protein $(1-100 \mathrm{ng} / \mathrm{ml})$ for 15 min. Subsequently, tubular cell MAPK activity was assayed. gp 120 promoted the activity of p38 MAPK in a dose-dependent manner (Fig. 4A). gp120 also promoted phosphorylation of p38 MAPK (Fig. 4A).
To determine the time course effect of gp120, equal numbers of cells were incubated with either buffer (control) or gp 120 protein $(10 \mathrm{ng} / \mathrm{ml})$ for variable time periods $(0,0.5,1,3,5,10,15,30$, and $60 \mathrm{~min})$. Subsequently, the samples were processed for kinase assay. gp120 enhanced the activation of p38MAPK in a time-dependent manner (Fig. 4B). gp120 also promoted phosphorylation of p38 MAPK in a time-dependent manner (Fig. 4B).

To evaluate the role of $\mathrm{p} 38$ MAPK activation, we studied the effect of SB 202190, a selective inhibitor of p38 MAPK, on gp120-induced MAPK activity. Equal numbers of growth-arrested tubular cells were treated with either buffer (control), or gp 120 protein $(10-100 \mathrm{ng} / \mathrm{ml})$ with or without SB $202190(1,5$, and $10 \mu \mathrm{M})$ for $18 \mathrm{hr}$. Subsequently, the samples were processed for kinase assay. gp120 $(10-100 \mathrm{ng} / \mathrm{ml})$ promoted kinase activity in tubular epithelial cells. At higher concentrations, SB 202190 completely inhibited the gp120 (100 ng/ml)-induced kinase activity (Fig. 4C).

\section{Studies Pertaining to Caspase-3 Activity}

To evaluate the role of caspase- 3 in gp120-induced tubular cell apoptosis, tubular cells were treated with either buffer or gp120 (1.0-100.0 ng/ml) for $16 \mathrm{hr}$. Subsequently, cells were harvested and caspase- 3 activity was measured. gp120 enhanced caspase-3 activity in a dose-dependent manner (Table 1).

\section{Discussion}

The present study demonstrates that gp120 promoted tubular cell apoptosis through CD4 receptors. Because gpl20-induced tubular cell apoptosis as well as P38 MAPK phosphorylation was inhibited by SB 202190, it appears that the gp120-induced downstream signaling proceeds through P38 MAPK activation.

HIV-1 usually targets CD4 receptors for its entry into a cell (16). Interaction of gp 160 with CD4 receptors not only facilitates entry of the virus, but also initiates the chain of events including syncitium formation, interference with signaling pathways, cytopathic effects, and priming of cells for apoptosis (16-20). Because pretreatment of gp160 with soluble CD4 attenuated the majority of the effects of HIV-1, it appears that the effects of gp 160 protein are mediated through CD4 receptors (20). Moreover, gp 160 protein has been reported to activate NF- $\kappa$ B through its interaction with CD4 (20).

HIVAN is accompanied by significant tubular abnormalities, including microcystic dilatation of tubules, apoptosis, necrosis, and proliferation of tubular cells $(31,32)$. Because mice transgenic for HIV-1 genes developed renal lesions similar to those found in HIVAN, Ray et al. (33) have suggested that the HIV-1 infection of tubular cells is not essential for the development of tubular lesions. We previously reported that HIV-1 gp160 envelope protein stimulated 
A

$$
\text { HIV-1 gp120 (ng/ml) } \quad 0 \quad 1 \quad 10 \quad 100
$$

\section{ATF-2 \\ p-p38MAPK}

Total-p38MAPK
B
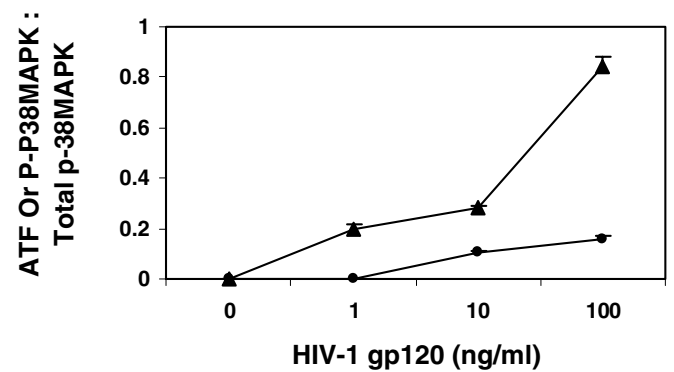

$\multimap$ ATF: Total p38MAPK $\rightarrow$ p-p38 : Total p38MAPK

$\begin{array}{llllllllll}\text { Time (min) } & 0 & 0.5 & 1 & 3 & 5 & 10 & 15 & 30 & 60\end{array}$

C

ATF-2

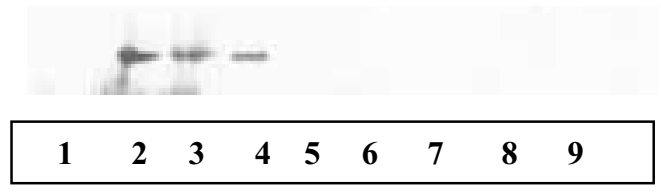

$40 \mathrm{kDa}$

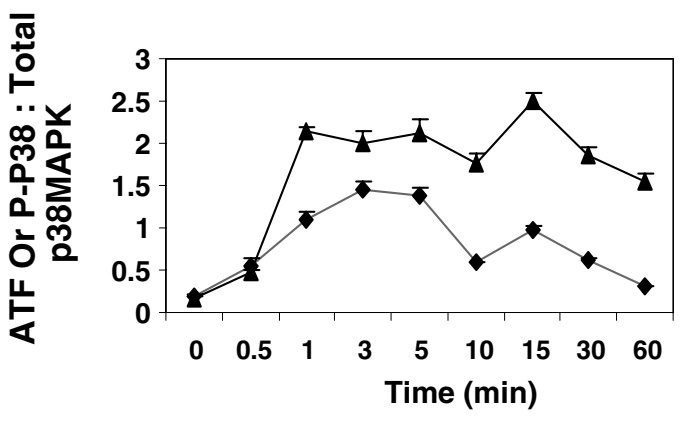

$\multimap$ ATF : Total p38MAPK —P-P38 : Total P38MAPK

Fig. 4. (A) Dose-response effects of gp120 on tubular cell p38 MAPK phosphorylation/activation. Equal numbers of tubular cells were incubated in media containing gp $120(1,10$, and $100 \mathrm{ng} / \mathrm{ml})$ for $1 \mathrm{hr}$. Subsequently; cells were lysed and processed for p38 MAPK activity. P38 MAPK activity in cultured human proximal tubular cells was measured by an in vitro immunokinase assay using ATF-2 as the substrate for the reaction. The upper panel shows the effect of gp 120 on the activation of p38 MAPK. Middle panel: Western blot using specific phospho-antibody to p38 MAPK. Equal numbers of tubular cells were incubated in media containing variable concentrations of gp120 (0-100 ng/ml) for $1 \mathrm{hr}$. At the end of the incubation period, cells were lysed, immunoprecipitated with phosphop38 MAPK antibody, and probed for p38 MAPK. The middle panel shows the effect of gp120 on tubular cell p38 MAPK phosphorylation. The lower panel shows total p38 MAPK activity. The line diagram shows the cumulative data of three experiments. (B) Time course effects of gp 120 on phosphorylation of tubular cell activation of p38 MAPK. P38 MAPK activity in human proximal tubular cells was measured by an in vitro immunokinase assay using ATF-2 as the substrate for the reaction. Equal numbers of tubular cells were incubated in media containing gp120 $(10 \mathrm{ng} / \mathrm{ml})$ for indicated time periods. Subsequently, cells were lysed and processed for p38 MAPK activity. The upper panel shows the effect of gp120 on the activation of tubular cell p38 MAPK. Middle panel: Western blot using specific phospho-antibody to p38 MAPK. Equal numbers of tubular cells were incubated in media containing gpl20 (10 ng/ml) for indicated time periods. At the end of the incubation periods, cells were lysed, immunoprecipitated with phospho-p38 MAPK antibody, and probed for p38 MAPK. The middle panel shows the effect of gp120 on tubular cell p38 MAPK phosphorylation. The lower panel demonstrates total p38 MAPK activity. The line diagram shows the cumulative data of three experiments. (C) Effect of SB 202190 on tubular cell p38 MAPK activity (by in vitro immunokinase assay using ATF-2 as a substrate for the reaction). Equal numbers of tubular cells were incubated in media containing either buffer (control; lane 1); gp120 (10 and 100 ng/ml; lanes 2 and 3 respectively); gp120, $100 \mathrm{ng} / \mathrm{ml}+\mathrm{SB} 202190,1 \mu \mathrm{M}$ (lane 4); gp120, $10 \mathrm{ng} / \mathrm{ml}+\mathrm{SB} 202190,1 \mu \mathrm{M}(\mathrm{lane} 5) ; \mathrm{gp} 120,100 \mathrm{ng} / \mathrm{ml}+\mathrm{SB}$ 202190, $5 \mu \mathrm{M}$ (lane 6); gp 120, $10 \mathrm{ng} / \mathrm{ml}+\mathrm{SB} 202190,5 \mu \mathrm{M}$ (lane 7); gp 120, $100 \mathrm{ng} / \mathrm{ml}+\mathrm{SB} 202190,10 \mu \mathrm{M}$ (lane 8); or gp120, $10 \mathrm{ng} / \mathrm{ml}+\mathrm{SB} 202190,10 \mu \mathrm{M}$ (lane 9).

the proliferation of human proximal tubular cells (12). Moreover, gp 160 protein also modulated matrix production by tubular cells (21). However, in those studies, we did not evaluate the role of CD4 receptors. Retrospectively, it appears that gp 160 may have interacted through CD4 receptors.

Conaldi et al. (9), in their pioneer studies, demonstrated that HIV-1 could actively replicate in proximal tubular cells and mesangial cells. However, the outcome of HIV-1 infection was different in these two cells (8). HIV-1 infection promoted renal tubular cell death through apoptosis, but did not produce any cytopathic effects in mesangial cells. On the other hand, we previously reported that HIV-1 gpl60 envelope protein enhanced the apoptosis of mesangial cells (34). This discrepancy in the 
Table 1. Dose-response effect of gp 120 on tubular cell caspase- 3 activity.

\begin{tabular}{lccc}
\hline & \multicolumn{3}{c}{$\operatorname{gp} 120(\mathrm{ng} / \mathrm{ml})$} \\
\cline { 2 - 4 } Control & 1.0 & 10.0 & 100.0 \\
\hline $2.3 \pm 0.3$ & $2.0 \pm 0.1$ & $5.2 \pm 0.1^{*}$ & $10.6 \pm 0.3^{* *}$
\end{tabular}

Equal numbers HK-2 cells were incubated in media containing either buffer (control) or gp 120 (1, 10, and $100 \mathrm{ng} / \mathrm{ml}$ ) for $16 \mathrm{hr}$. At the end of the incubation period, cells were harvested and prepared for the measurement of caspase- 3 activity with the use of caspase- 3 assay kit. Results (means \pm SEM $\mu$ M release of caspase-3) are from four sets of experiments.

${ }^{*} p<0.001$ compared with control, gp120, $1 \mathrm{ng} / \mathrm{ml}$ and gp120, $100.0 \mathrm{ng} / \mathrm{ml}$.

** $p<0.001$ compared with control and gp120, 1.0 and $10.0 \mathrm{ng} / \mathrm{ml}$.

observations may be related to the use of different techniques for the evaluation of apoptosis. Conaldi et al. (9) used acridine orange to detect the cytopathic effect of HIV-1 on mesangial cells, whereas we utilized $\mathrm{H}-33342$, a specific dye, for morphologic evaluation of apoptosis in mesangial cells (34). Use of acridine orange makes it difficult at times to distinguish between apoptotic and necrotic cells.

HIV-1 has been demonstrated to trigger tubular cell apoptosis $(9,11,35)$. Studies by Bruggeman et al. (36), in which they transplanted kidneys between normal and HIV-transgenic mice showed that only the kidney containing the HIV-transgene develops renal lesions that mimic HIVAN. This emphasizes that the presence of HIV-1 gene products in renal cells is necessary and sufficient in the development of renal lesions in HIVAN. Barisoni et al. (37) demonstrated that glomerular and tubular epithelial cells express HIV-l transgene early in the disease process while the renal architecture is still preserved. As the disease progresses, many tubular cells develop apoptosis and also lose transgene expression. Interestingly, tubular epithelial cells in microcysts show mislocalization of $\mathrm{Na}^{+}, \mathrm{K}^{+}$-ATPase expression (37). These studies suggest that both glomerular and tubular epithelial cells are the primary targets of HIV-1 in the pathogenesis of HIVAN (37).

In renal disease, MAPKs have been shown to be activated in response to both growth factors and proinflammatory cytokines in a number of pathologic conditions (38-41). Phosphorylation of MAPKs are not only limited to the cell culture environment, but activation of these enzymes has also been reported in the intact tissue by diverse stimuli (41-43). In the present study, gp120 promoted not only the activity but also the phosphorylation of p38 MAPK. The biological significance of this activation was confirmed by SB 202 190-induced inhibition both under basal and gp120-induced stimulated states. The effect of SB 202190 on tubular cell p38 MAPK phosphorylation was dose dependent. In another study of human proximal tubular cells, pretreatment with SB $202190(10 \mu \mathrm{M})$ had a small effect on basal or TNF- $\alpha$-stimulated phosphorylation of p38 MAPK but completely abolished TNF- $\alpha$-stimulated p38 MAPK activity (44).

What is the significance of the present study? Conaldi et al. (8) demonstrated the presence of CD4 receptors on tubular cells; the present study not only confirms their observations on cultured tubular cells, but also demonstrates the presence of CD4 receptors on tubular cells in intact renal tissue. Moreover, the present study highlights the functional role of $\mathrm{CD} 4$ receptors in the induction of tubular cell injury.

We conclude that gp120, through interaction with CD4, triggers tubular cell apoptosis. This effect of gp 120 seems to be mediated through tubular cell p38 MAPK phosphorylation.

\section{Acknowledgment}

The present study was supported by the grant ROI DA 12111 from the National Institutes of Health. Part of this work was presented at the 31st, 32nd, and 33rd Annual Meetings of the American Society of Nephrology.

\section{References}

1. Rappaport J, Kopp JB, Klotman PE. (1994) Host virus interactions and the molecular regulation of HIV-l: role in the pathogenesis of HIV-associated nephropathy. Kidney Int. 46: 16-27.

2. Rao TK, Filippone EJ, Nicastri AD, et al. (1984) Associated focal and segmental glomerulosclerosis in the acquired immunodeficiency syndrome. N. Engl. J. Med. 310: 669-673.

3. Dickie P, Felser J, Eckhaus M, et al. (1991) HIV-associated nephropathy in transgenic mice expressing HIV-1 genes. 185: 109-119.

4. Bourgoignie JJ, Pardo V. (1991) The nephropathology in human immunodeficiency virus (HIV-1) infection. Kidney Int. 40(suppl): S19-S23.

5. Kimmel PL, Phillips TM, Ferreira-Centeno A, FarkasSzlallasi T, Abraham AA, Garrett CT. (1993) HIV-associated immune mediated renal disease. Kidney Int. 44: 1327-1340.

6. Cohen AH, Sun NCJ, Shapsak P, Imagawa DT. (1989) Demonstration of human immunodeficiency virus in renal epithelium in HIV-associated nephropathy. Mod. Pathol. 2: 125-128.

7. Bruggeman LA, Ross MD, Tanji N, et al. (2000) Renal epithelium is a previously unrecognized site of HIV-1 infection. $J$. Am. Soc. Nephrol. 11: 2079-2087.

8. Ray PE, Liu XH, Henry D, et al. (1998) Infection of human primary renal epithelial cells with HIV-1 from children with HIV-associated nephropathy. Kidney Int. 53: 1217-1229.

9. Conaldi PG, Biancone L, Bottelli A, et al. (1998) HIV-1 kills tubular epithelial cells in vitro by triggering an apoptotic pathway involving caspase activation and Fas upregulation. J. Clin. Invest. 102: 2041-2049.

10. Kapasi A, Singhal PC. (1998) Human renal tubular epithelial cells express CD4 receptors. J. Am. Soc. Nephrol. 9: 459A.

11. Kapasi A, Fan S, Singhal PC. (2000) HIV-1 gp 120 induces activation of AP-1 and NF- $\kappa$ B in proximal tubular cells. J. Am. Soc. Nephrol. 11: 479A.

12. Singhal PC, Sharma P, Singhal M, Gibbons N, Kapasi A, Reddy K. (1997) HIV-1 gpl60 protein modulates proximal tubular cell proliferation and matrix synthesis. Cell Physiol. Biochem. 7: 43-52. 
13. Bredesen DA. (1995) Neural apoptosis. Ann. Neurol. 38: 839- 851.

14. Xia Z, Dickens M, Raingeaud J, Davis RJ, Greenberg ME. (1995). Opposing effects of ERK and JNK-p38 MAP kinases on apoptosis. Science 1: 1326-1331.

15. Su B, Karin M. (1996) Mitogen-activated protein kinase cascades and regulation of gene expression. Curr. Opin. Immunol. 8: $402-411$.

16. Capons DJ, Ward RH. (1991) The CD4-gpl20 interactions and AIDS pathogenesis. Ann. Rev. Immunol. 9: 649-678.

17. Habeshaw JA, Dalgleish AG, Bountiff L, et al. (1990) AIDS Pathogenesis: HIV envelope and its interaction with cell proteins. Immunol. Today 11: 418-425.

18. Pinching AJ, Nye KE. (1991) Defective signal trnasduction: a common pathway for cellular dysfunction in HIV infection. Immunol. Today 11: 256-259.

19. Sodroski J, Goh WC, Rosen C, Campbell K, Haseltine A. (1986) Role of HTLV-III/LAV envelope in synctium formation and cytopathy. Nature (Lond) 332: 470-474.

20. Chirmule N, Kalyanraman VS, Pahawa S. (1994) Signal transduced through the CD4 molecule on T lymphocytes activates NF-kB. Biochem. Biophys. Res. Commun. 203: 498-504.

21. Lannuzel A, Barnier JV, Hery C, et al. (1997) Human immunodefficiency virus type 1 and its coat protein gpl20 induce apoptosis and activate JNK and ERK Mitogen-activated protein kinases in human neurons. Ann. Neurol. 42: 847-856.

22. Gupta S, Campbell D, Derijard B, Davis RJ. (1995) Transcription factor ATF2 regulation by the JNK signal transduction pathway. Science 267: 389-393.

23. Terada Y, Kimio T, Homma MK, et al. (1994) Sequential activation of Raf-1 kinase, mitogen-activated protein kinase kinase, MAP kinase, and S6 kinase by hyperosmolality in renal cells. J. Biol. Chem. 272: 31296-31301.

24. Ding G, Van Goor H, Orlowski JM, Diamond JR. (1997) Oxidized LDL stimulates the expression of TGF- $\beta$ and fibronectin in human glomerular epithelial cells. Kidney Int. 51: 147-154.

25. Singhal PC, Reddy K, Franki N, Ding G. (1999) HIV-1 gp 120 envelope protein modulates proliferation of human glomerular epithelial cells. J. Cell Biochem. 76: 61-70.

26. Kapasi A, Franki N, Ding G, Singhal PC. (1999) Human glomerular epithelial cells express CD4 and interaction with gp 120 protein promotes PYK2 tyrosine phosphorylation. Mol. Cell. Biol. Res. Commun. 1: 140-143.

27. Singhal PC, Sharma P, Kapasi AA, Reddy K, Franki N, Gibbons N. (1998) Morphine enhances macrophage apoptosis. J. Immunol. 160: 1886-1893.

28. Chomczynski P, Sacchi N. (1987) Single-step method of RNA isolation by guanidinium thiocynate-phenol-chloroform extraction. Anal. Biochem. 161: 156-159.

29. Lander HM, Jacovina AT, Davis RJ, Tauras JM. (1996) Differential activation of mitogen-activated protein kinases by nitric oxide-related species. J. Biol. Chem. 271: 19705-19709.

30. Gomez N, Cohen P. (1991) Dissection of the protein kinase cascade by which nerve growth factor activates MAP kinases. Nature 353: 170-173.
31. Cohen AH, Nast CC. (1984) HIV-associated nephropathy: A unique, combined glomerular, tubular and interstitial lesion. Mod. Pathol. 1: 87-97.

32. D'Agati V, Suh JI, Carbone L, Cheng JT, Appel G. (1989) The pathology of HIV-associated nephropathy: a detailed morphologic and comparative study. Kidney Int. 35: 13581370.

33. Ray PE, Bruggeman LA, Weeks BS, et al. (1984) Role of bFGF and its low affinity receptors in the pathogenesis of HIVassociated nephropathy in transgenic mice. Kidney Int. 46: 759-772.

34. Singhal PC, Sharma P, Reddy K, Franki N, Kapasi A, Gibbons N. (1997) HIV-1 gp 160 protein modulates mesangial cell proliferation and apoptosis. Nephron 76: 284-295.

35. Kapasi A, Fan S, Singhal PC. (2000) Interaction between TGF- $\beta /$ Smads and $\mathrm{p} 300 / \mathrm{CBP}$ play a role in HIV-1 gp120-induced proximal tubular cell apoptosis. J. Am. Soc. Nephrol. 11: 2409A.

36. Bruggeman LA, Dikman S, Meng C, Quaggin SE, Coffman TM, Klotman PE. (1997) Nephropathy in human immunodefficiency virus-1 transgenic mice is due to renal transgene expression. J. Clin. Invest. 100: 84-92.

37. Barisoni L, Bruggeman LA, Mundel P, D'Agati VD, Klotman PE. (2000) HIV-1 induces renal epithelial dedifferentiation in a transgenic model of HIV-associated nephropathy. Kidney Int. 58: $173-181$.

38. Schramek H, Sorokin A, Watson RD, Dunn MJ. (1996) Differential long-term regulation of MEK and of p42 MAPK in rat glomerular mesangial cells. Am. J. Physiol. 270: C40C48.

39. Huweiler A, Pfeilschifter J. (1994) Transforming growth factor $\beta$ stimulates acute and chronic and activation of the mitogen-activated protein kinase cascade in rat mesangial cells. FEBS Lett. 354: 255-258.

40. Schramek H, Feifel HE, Pollack V. (1997) Constitutively active mutant of the mitogen activated protein kinase kinase MEKl induces epithelial cell dedifferentiation and growth inhibition in MDCK-C7 cells. J. Biol. Chem. 272: 11426-11433.

41. Bokemeyer D, Sorokin A, Dunn MJ. (1996) Multiple intracellular MAP kinase signaling cascades. Kidney Int. 49: 1187-1198.

42. Bonventre JV, Force T. (1998) Mitogen activated protein kinases and transcriptional responses in renal injury and repair. Curr. Opin. Nephrol. Hypertens. 7: 425-433.

43. Hannken T, Schroeder R, Zahner G, Rolf A, Stahl K, Wolf G. (2000) Reactive oxygen species stimulate p44/42 Mitogenactivated protein kinase and induce $\mathrm{p} 27^{\mathrm{Kip} 1}$ : role in angiotensin II-mediated hypertrophy of proximal tubular cells. J. Am. Soc. Nephrol. 11: 1387-1397.

44. Leonard M, Ryan MP, Watson AJ, Schramek H, Healy E. (1999) Role of MAP kinase pathways in mediating IL-6 production in human primary mesangial and proximal tubular cells. Kidney Int. 56: 1366-1377. 